\title{
The Activator Optimization of Low-temperature SnBi Lead-free Solder Paste
}

\author{
Yan Jiang ${ }^{1, a}, K_{\text {Ke Shan }}^{1, b}$, Li-da Sun ${ }^{1, c}$, Zi-jing Li ${ }^{1, d}$, Rui-ming Xiao,e \\ ${ }^{1}$ College of science, HongHe University, Mengzi, Yunnan, 661100, China \\ aemail: jiangyan1626@126.com, ${ }^{\text {bemail: 397910098@qq.com, }{ }^{c} e m a i l: ~ s u n l i d a 05 @ 126 . c o m, ~}$ \\ demail: lizijing1@gmail.com, eemail: 290691217@qq.com
}

Keywords: Lead-free solder paste; activator; performance

\begin{abstract}
The optimization of activator used in SnBi lead-free solder paste were carried out by welding experiments with the spreadability and the spot morphology as the main comment indexes.And the properties of the composite activator which was mixed by two activator possessing good performances were studied. The results indicated that the pastes with succinic acid and salicylic acid for as single activator have low wettability, the surface is easily oxidized;When (succinic acid : salicylic acid) is 2:3,the solder paste has good weldability and the spreadabilities are $83 \%$.The appearance of spots is regular,plump,beamy and less surface oxide.
\end{abstract}

\section{Introduction}

Lead-free solder paste is the key to the electronic product surface assembly welding materials, the development of its support of the flux has become an urgent task in the field of electronic assembly surface [1]. Flux at home and abroad is composed by the activator, solvents, film former, surfactant, anti oxidant and corrosion inhibitor ect [2].Activator is used to remove the pad and the solder surface oxides in the brazing temperature, so as to improve the wettability between solder and pad,and prevent oxidation during reflow soldering before solder joints were formed [3].Activator is choiced by three main ways that include the experiment of heating quality analysis, the combination of different organic acids and the combination of organic acid and organic amine [4].It is that good performance of organic activator was optimited by the experiment of heating quality analysis, then properties of single activator and compound activator were studied.

\section{Experimental And Materials}

\section{The Preparation of Flux}

The weighed 33\% rosin, 10\% activator (succinic acid, salicylic acid),solvents (tetrahydrofurfuryl alcohol, isopropanol, ethanol , diethylene glycol monobutyl ether), regulator triethanolamine, $0.6 \%$ inhibitor BTA, 2\%surfactant sodium lauryl diethylene glycol ether , $0.4 \%$ hydroquinone antioxidants were leted into beaker with certain ratio.The beaker was covered with fresh-keeping film,which was heated and stirred on constant temperature magnetic stirrer ,and cooled to room temperature formed the flux finally.

\section{The Paster of Flux}

Accurately weigh Sn42Bi58 alloy powder and flux according to the ratio of $8: 1$, which pour into $50 \mathrm{~mL}$ beakerand stir $5 \mathrm{~min}$ with a glass rod, so that the solder powder and flux are fully mixed evenly and then standing 3min, solder paste was made.

\section{Flux Performance Testing}

\section{1)The Stability of The Flux}

Under room temperature, the flux is a transparent light yellow viscous liquid with a certain viscosity. The flux is stirred for several minutes, so that it is fully mixing. Then taked $50 \mathrm{ml}$ sample into the $100 \mathrm{ml}$ tube, which is covered tightly and leted in the cooler cooling to $(5+2){ }^{\circ} \mathrm{C}$ keeping $60 \mathrm{~min}$, and then observe under this temperature flux that have obvious stratification or crystal 
precipitation phenomenon. Open the tube cover, the sample is puted in without air circulation oven, under $(45+2){ }^{\circ} \mathrm{C}$ keeping 60 min. Then the flux is no delamination was observed at this temperature . Thus, the flux has good stability.

\section{2) Determination of Non-volatile Materials[5]}

Non-volatile Materials refer to the content of the solid residue flux at a certain temperature. Accurately weighed the $6 \mathrm{~g}$ flux $\left(\mathrm{m}_{1}\right)$,which was droped into a volume of $25 \mathrm{ml}$ in the melting pot and heated in boiling water bath so that most of it's solvent was evaporated.Puted the flux in (110 $\pm 2){ }^{\circ} \mathrm{C}$ ventilation oven and dried within $4 \mathrm{~h}$,which taked out and placed in a drying oven for cooling to room temperature, which dried and weighed repeatedly until the error is kept within $+/-$ $0.05 \mathrm{~g}$ as a constant, this specimen quality is $\mathrm{m}_{2}$.

Were done in both samples, the average value of flux is non-volatile matter content value .

Mamely: $\quad \mathrm{W}=\mathrm{m}_{2} / \mathrm{m}_{1} \mathrm{x} 100 \%$

Type: $\mathrm{m} 1$ is the initial mass of the sample ; $\mathrm{m} 2$ is constant when the quality of the sample after drying

\section{3) Non-viscosity Test[5]}

Flux is coated on the the copper $(50 \mathrm{mmx} 50 \mathrm{mmx} 0.5 \mathrm{~mm})$, where chalk ash were spreaded on and wiped with gauze. It is indicated that the non-viscosity of flux is eligible if the copper has no traces of gauze.

\section{Spreadability of Paste Test[6]}

The copper test piece was cut $30 \mathrm{mmx} 30 \mathrm{mmx} 0.5 \mathrm{~mm}$ flat, with a \# 500 sand paper to remove the oxide film , which is polished with a polishing paste, and then cleaned with ethanol and dried in oven.

The copper piece was placed in a temperature of $(150 \pm 2){ }^{\circ} \mathrm{C} \quad$ in the oven oxidation of $1 \mathrm{~h}$, all specimens should be placed on the same level of the oven .Taked proper solder paste with a glass rod on the copper,which puted on scale to photo,and placed $250{ }^{\circ} \mathrm{C}$ high temperature box type resistance furnace. After holding $5 \mathrm{~min}$,it was taked out cooling to room temperature in the air and put on scale pictures.

The photos were upload to computer, which clipped with Microsoft office Word, and then imported AutoCAD inorde to determinate spreading area utilizing query function of AutoCAD.Finally, spreadability of flux was calculated.

\section{Results And Discussion}

\section{Physical Properties of Flux}

It shows that the impact of single activator and compound activator on the properties of flux fromTab. 1

As can be seen from Tab.1, the flux was prepared by single activator or compound activator,which has weak corrosion, qualified non-viscosity and non-volatile naterials that can satisfy GB/T15829-1995 "soft soldering using fiber material " requirements, wherein the fraction of non- volatile matter content is not more than $15 \%$ [ 7 ] .

Tab.1 The testing results of physical properties of flux

\begin{tabular}{cccccc}
\hline number & $\begin{array}{c}\text { mass ratio of } \\
\text { activator } \\
\text { succinic acid: } \\
\text { salicylic acid }\end{array}$ & stability & corrosion & non-viscosity & $\begin{array}{c}\text { non-volatile } \\
\text { materials/\% }\end{array}$ \\
\hline a & $1: 0$ & non delaminating & less & qualified & \\
b & $0: 1$ & non delaminating & less & qualified & 5.2 \\
c & $2: 1$ & non delaminating & less & qualified & 4.9 \\
d & $3: 7$ & non delaminating & less & qualified & 4.6 \\
e & $4: 1$ & non delaminating & less & qualified & 5.3 \\
f & $2: 3$ & non delaminating & less & qualified & 4.7 \\
\hline
\end{tabular}




\section{The Influence of Activator Rratio on The Welding Performance of Solder Paste}

As can be seen from Tab.2, Solder paste were with single activator, which has poor wettability, low spreadability and many residue;while solder paste prepared with compound activator has good wettability, of which spreadability can reach $83 \%$, and bright spot and regular morphology.

It is because that single activator difficult to play activity in the whole welding process, whole different boiling point of compound activator can make the flux with different activation temperature gradient; low-temperature activator has activity in welding at low temperature, which can induce and stimulate high-temperature activator, so that the activator in the welding of the whole temperature range has active [8].

However , the greater ratio of succinic acid , the more the residue around the solder joints in complex formulation ; It caused the solder joint with defects and increased non-volatile materials of flux. Comprehensive consideration, the most suitable ratio of succinic acid and salicylic acid is 2:3 or 3:7.

Tab.2 Morphology of solder joint prepared with different proportion of Activator

\begin{tabular}{cccccccc}
\hline activator & $\mathrm{A}$ & $\mathrm{B}$ & $\mathrm{C}$ & $\mathrm{D}$ & $\mathrm{E}$ & $\mathrm{F}$ \\
\hline $\begin{array}{c}\text { Morphology of } \\
\text { solder joint } \\
\text { Spreadability } \%\end{array}$ & & & & & & & \\
\hline
\end{tabular}

\section{The Microscopic Influence of Activator Rratio on Interface Layer of Solder joint}

It can be shown from Fig. 1 that activator ratio has great influence on the reaction layer of solder joints .Perpared Solder is with a, b, f group formula, of which diffusion layer of solder joint was flat and smooth, no obvious hole and crack defects, but spreadability of a, b, f group is poorer; Solder perpared with c、d、e group formula, of which diffusion layer of solder joint is not flat and there are cracks, holes.

It can be seen from Fig. 1 and Tab.3 that the interface layer between the brazing solder and the $\mathrm{Cu}$ layer of the substrate is 3, A interface of the substrate layer is a $\mathrm{Cu}$ layer, a high atomic concentration of $\mathrm{Cu}$; B layer is closed to the copper substrate, where solder and $\mathrm{Cu}$ substrate have been reaction in the process of welding, $\mathrm{Sn}$ and $\mathrm{Cu}$ atomic are interdiffused so as to generate IMC.It has been studied that the IMC is Cu3Sn[9].C layer is fiber material layer, where $\mathrm{Cu}$ substrate metal is dissolved to fiber; It shows that the element diffuse fully and the fiber material spread well on the surface of $\mathrm{Cu}$ substrate during welding process.

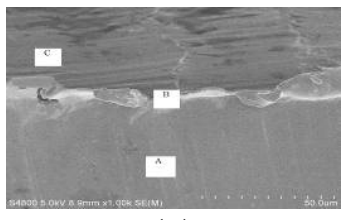

(a)

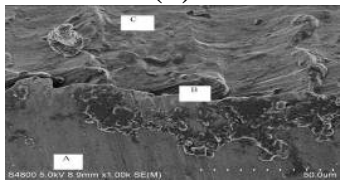

(d)

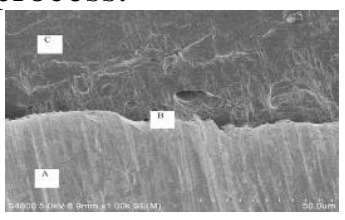

(b)

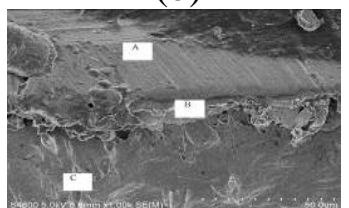

(e)

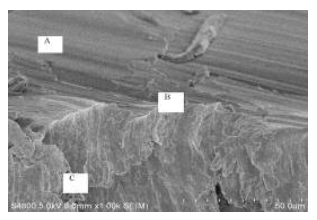

(c)

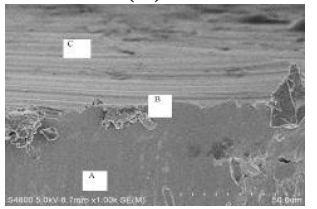

(f)

Fig.1 SEM photos of solder joint prepared by different ratio ofactivator Tab.3 The energy spectrum analysis of solder joint cross section

\begin{tabular}{ccccccc}
\hline \multirow{2}{*}{ element } & \multicolumn{2}{c}{$\mathrm{A}$} & \multicolumn{2}{c}{$\mathrm{B}$} & $\mathrm{C}$ \\
\cline { 2 - 7 } & $\mathrm{wt} / \%$ & $\mathrm{at} / \%$ & $\mathrm{wt} / \%$ & $\mathrm{at} / \%$ & $\mathrm{wt} / \%$ & $\mathrm{at} / \%$ \\
\hline $\mathrm{Cu}$ & 100 & 100 & 60.43 & 74.02 & 19.65 & 17.25 \\
$\mathrm{Bi}$ & 0 & 0 & 31.98 & 6.43 & 59.64 & 63.31 \\
$\mathrm{Sn}$ & 0 & 0 & 7.59 & 19.55 & 20.71 & 19.44 \\
\hline
\end{tabular}

Therefore, when succinic acid :salicylic acid=2:3 in activator,Sn42Bi58 solder has best spreadability and weldability on Cu substrate. 


\section{Conclusion}

(1)When the rosin, solvents, corrosion inhibitors, surface active agent are added quantitatively in self- flux , performance of solder prepared with compound activator is superior to single activator. the solder paste has good spreadabilities, full solder joint and few non-volatile materials.

(2)When the mass ratio of compound activator of succinic acid and salicylic acid is 2:3,solder joint of welding s smooth and good welding quality; Spreadability of prepared SnBi solder paste can reach $83 \%$ on the copper plate.

(3)Showed from the cross section morphology of solder joint, which solder alloy and the substrate occur reaction-diffusion and generate IMC layer resultly.

\section{Acknowledgement}

In this paper, the research was sponsored by the Application Foundation of Yunnan Province (Project No. 2013FZ123)

\section{References}

[1]Yan Jian,Wuzhi Bin,Huang Yan,et, Development progress of lead-free solder paste[J].Che mical Research and Application,2006,18(5)472-447.

[2]Gao Si,Progress in Research of Flux Compositions,Printed Circuit Information[J].SMT,200 9,(9)59-62.

[3]Jing Xia,Guojian Jun,Guxiao Long,et,Discussion for mechanism of paste fluxduring solderi ng[J].Welding Technology,2009,38(10)38-41.

[4]Jing Xia,The function and performance of activitor in solder paste[J]. Journalof Zhejiang Metallurgy,2009,(4)13-15.

[5]Jiuyong Tao,Yannian Fu,Chenyang Yang,CH.Effect of rosin on Physical Properties of Znbased Flux and Spreadability of Zn20Sn Solder[J].Welding Technology ,2013,42(7)9-12.

[6]Qianguo Tong,Xuejian Ping,Zhanguo Fu,et.Application of Computer Graphic Technology i $\mathrm{n}$ Measurement of Tin Solder Spreading Area[J]. Shanghai Nonferrous Metals,2009,30(3)119121.

[7]Jiuyong Tao,Yannian Fu,Chenyang Yang,Effect of Acative agent on PhysicalProperties of Zn-based Flux and Spreadability of Zn20Sn Solder[J].Journal of Henan University of Scienc e and Technology: Natural Science ,2013,34(2)8-12.

[8]Lihai Pu,Qinchun Yang,Q.Mechanism exploration on design of new fluxes[J]. Electronic C omponents \& Materials, 2013,32(2)66-69.

[9]Liuchun Zhong, Zhang Wei,Suiman Ling,et.Bi segregation at interface of theeutectic SnBi/ $\mathrm{Cu}$ solder joint[J]. Acta Metallurgica Sinica,2005,41(8)847-852. 